BMJ Nutrition, Prevention \& Health

\section{Dietary micronutrients in the wake of COVID-19: an appraisal of evidence with a focus on high-risk groups and preventative healthcare}

To cite: McAuliffe S, Ray S, Fallon $\mathrm{E}$, et al. Dietary micronutrients in the wake of COVID-19: an appraisal of evidence with a focus on high-risk groups and preventative healthcare. BMJ Nutrition, Prevention \& Health 2020;3:e000100. doi:10.1136/ bminph-2020-000100

For numbered affiliations see end of article.

Correspondence to Shane McAuliffe, NNEdPro Global Centre for Nutrition and Health, St John's Innovation Centre, Cambridge CB4 OWS, UK;

s.mcauliffe@nnedpro.org.uk and

Professor Sumantra Ray, NNEdPro Global Centre for Nutrition and Health, St John's Innovation Centre, Cambridge CB4 OWS, UK;

s.ray@nnedpro.org.uk

SR and MK are joint senior authors.

Received 4 May 2020

Revised 23 May 2020

Accepted 1 June 2020 Published Online First 18 June 2020

\section{ABSTRACT}

Existing micronutrient deficiencies, even if only a single micronutrient, can impair immune function and increase susceptibility to infectious disease. Certain population groups are more likely to have micronutrient deficiencies, while certain disease pathologies and treatment practices also exacerbate risk, meaning these groups tend to suffer increased morbidity and mortality from infectious diseases. Optimisation of overall nutritional status, including micronutrients, can be effective in reducing incidence of infectious disease. Micronutrient deficiencies are rarely recognised but are prevalent in the UK, as well as much more widely, particularly in high-risk groups susceptible to COVID-19. Practitioners should be aware of this fact and should make it a consideration for the screening process in COVID-19, or when screening may be difficult or impractical, to ensure blanket treatment as per the best practice guidelines. Correction of established micronutrient deficiencies, or in some cases assumed suboptimal status, has the potential to help support immune function and mitigate risk of infection. The effects of and immune response to COVID-19 share common characteristics with more well-characterised severe acute respiratory infections. Correction of micronutrient deficiencies has proven effective in several infectious diseases and has been shown to promote favourable clinical outcomes. Micronutrients appear to play key roles in mediating the inflammatory response and such effects may be enhanced through correction of deficiencies. Many of those at highest risk during the COVID-19 pandemic are also populations at highest risk of micronutrient deficiencies and poorer overall nutrition. Correction of micronutrient deficiencies in established COVID-19 infection may contribute to supporting immune response to infection in those at highest risk. There is a need for further research to establish optimal public health practice and clinical intervention regimens.

\section{INTRODUCTION}

Malnutrition contributes to poor health and disease outcomes, through dampening of our body's immune response and thereby increasing susceptibility to infection. ${ }^{1}$ This relationship has been appreciated for some time, with macronutrients (in particular protein) having a key part to play in the production of immune system cells. ${ }^{2}$ While the focus of this paper will primarily be on micronutrients, it is important to note, especially for higher risk groups such as older individuals, that adequate intake of both calories and protein will help prevent malnutrition, which is often community acquired and is associated with poor clinical outcomes for those admitted to secondary care. ${ }^{3}$ There has also been recent interest in the role of chronic conditions like obesity and diabetes in predicting poorer outcomes in COVID$19 .{ }^{4}$ With this in mind, optimising nutritional status through adequate provision of energy, protein and promoting good metabolic health should remain a priority, bearing in mind that individual requirements will of course be varied.

Emerging evidence suggests a role for micronutrients, in maintaining and improving immune function through a number of mechanisms. These include roles in the development and maintenance of physical barriers (skin and mucous membranes), production of antimicrobial proteins, activity of immune cells and mediation of inflammatory processes. A bidirectional relationship exists between nutrition and infection, whereby poor nutritional status predisposes one to infection and where infection is exacerbated by a poor nutritional status. Vitamins and minerals play a role in neutralising the effects of harmful oxidative agents that have the potential to damage cells. ${ }^{5}$ Deficiency of these nutrients suppresses immune function and increases our susceptibility to infection, creating a vicious cycle of deficiency and disease. ${ }^{6}$ While recently published work has dealt comprehensively with the role of micronutrients in immune function, ${ }^{7}$ this review will focus on a selection of nutrients that have 
previously been associated with infectious and respiratory diseases.

Infectious disease exists not just in the developing world, where this relationship is well established and micronutrient deficiencies are commonplace, but also in developed nations. The global impact of seasonal influenza amounts to between 3 and 5 million hospitalisations and is responsible for 290-650 thousand deaths per year. ${ }^{8}$ Acute respiratory tract infections (RTIs) account for approximately 2.65 million deaths annually, with lower respiratory tract infection (LRTI) the most common cause of sepsis related deaths globally from 1990 to $2017 .{ }^{910}$ For these reasons, it would appear that additional strategies for immune support during times for infection are warranted. In some cases, aiming for micronutrient intakes higher than the recommended dietary allowance (RDA) may be warranted in certain key micronutrients for high-risk population groups. ${ }^{11}$ This should be a consideration for the screening and treatment process in clinical practice and also for public health risk communication.

\section{Vitamin A}

Vitamin A plays a role in the regulation of the innate immune response (through natural killer (NK) cells, macrophages and neutrophils) and cell-mediated immunity (through the growth and differentiation of B cells). It is also active in humoral antibody immunity and in cytokine signalling, with a role in the inflammatory response as a result. ${ }^{12}$ Of particular relevance is its role in mucosal epithelium (skin and mucous membrane) integrity, which is compromised in vitamin A deficiency and leads to increased susceptibility to infection via the eyes, respiratory and gastrointestinal tract. ${ }^{13}$ Deficiency therefore contributes to increased vulnerability to infections such as measles, malaria and diarrhoeal diseases. ${ }^{14}$ It is a major public health problem in low/middle-income countries (LMICs) and is a leading cause of morbidity and mortality in women and children. ${ }^{14}$

Supplementation has been shown to be effective in all-cause mortality from infectious disease in children. ${ }^{15}$ Caution should be advised interpreting these results, however, as the majority of these studies have been carried out in nutrient-deficient children in LMICs.

\section{Vitamin C}

Vitamin $\mathrm{C}$ is an effective antioxidant due to its ability to readily donate electrons. ${ }^{16}$ This enhances the activity and function of immune cells, white blood cell migration and leucocyte function via neutrophil and monocyte mobilisation. ${ }^{17}$ It also has the potential to regenerate vitamin $\mathrm{E}$, which possesses important radical scavenging properties itself (see below). Vitamin C increases epithelial barrier function and promotes oxygen radical scavenging activity of skin. ${ }^{17}$ Deficiencies lead to impaired immunity and higher susceptibility to infection, increasing the risk of contracting pneumonia and also enhancing disease severity. ${ }^{18}$ The infection-related consequences of deficient vitamin $\mathrm{C}$ status are demonstrated clearly in chronic deficiency, otherwise known as scurvy, with pneumonia being one of the most frequent complications and causes of death. ${ }^{18}$ Infections also impact stores due to enhanced inflammation and metabolic requirements, ${ }^{17}$ meaning the effect of one can exacerbate the other and prolong illness.

Dysfunctional epithelial barrier function of the lungs of animals can be restored by vitamin C administration. ${ }^{19}$ Supplementation is effective in both prevention and treatment of RTIs, having been shown to reduce incidence and duration of upper respiratory tract infection (URTI) and severity of pneumonia in hospitalised older adults ${ }^{20}$ as well as symptoms of common cold..$^{21}$ Prophylactic supplementation with vitamin $\mathrm{C}$ has also proven to reduce the risk of acquiring pneumonia, ${ }^{22}$ resulting in calls for intakes above RDA for the treatment of established infections, which require higher levels to compensate for the increased metabolic demand. ${ }^{11}{ }^{16}$ Recent trial evidence, however, has demonstrated limited effects of high-dose supplementation on clinical endpoints in critically ill patients with acute respiratory distress syndrome (ARDS). ${ }^{23}$

\section{Vitamin D}

Observational data have suggested a longstanding association between vitamin $\mathrm{D}$ status and the incidence of airway infection, ${ }^{24}$ in particular indicating a strong relationship between low status and the susceptibility to RTIs. Vitamin D plays an important role in the innate immune system, through the production of antimicrobial peptides, including cathelicidin and defensins. ${ }^{25}$ This process is highly dependent on the status of tissues, which stimulate immune antibacterial activity in a variety of cell types by increasing the production of antimicrobial factors and by enhancing mechanisms associated with autophagy. ${ }^{26}$ Many cell types express vitamin D receptors, with particularly high levels existing in lung epithelial cells. Deletion has the potential to increasing lung permeability and reduce pulmonary barrier integrity. ${ }^{27}$ The activation of vitamin $\mathrm{D}$ in the lung has the potential to induce these antimicrobials and attenuate inflammatory cytokines in response to viruses. Higher vitamin D status is associated with decreased levels of proinflammatory cytokines and conversely low status appears to be associated with the activation of inflammatory processes, which is particularly relevant in the case of sepsis derived from lung infection. ${ }^{28}$

Supplementation of vitamin $\mathrm{D}$, particularly in those with lower baseline status, has proven effective in combating conditions like RTI ${ }^{29}$ tuberculosis, ${ }^{26}$ chronic obstructive pulmonary disease ${ }^{30}$ and asthma. ${ }^{31}$ Meta analyses of randomised controlled trials (RCTs) have shown that vitamin D supplementation significantly reduces the incidence of RTIs, with baseline status and dosing frequency found to be independent modifiers of risk. ${ }^{29}$ Effects of supplementation were found to be strongest in those with baseline status $<25 \mathrm{nmol} / \mathrm{L}$ and in groups who received daily supplementation-the latter also true in those with higher baseline status. ${ }^{29}$ 


\section{Vitamin $\mathrm{E}$}

Vitamin E protects the integrity of cell membranes from damage caused by free radicals. ${ }^{32}$ It has the potential to influence both innate and adaptive immunity ${ }^{33}$ - with alpha-tocopherol shown to specifically enhance the dampened immune response associated with ageing. ${ }^{34}$

Trial data on the effects of supplementation with vitamin $\mathrm{E}$ have been mixed, ${ }^{35}$ although has proven effective in reducing URTI in elderly care home residents. ${ }^{34}$ Improvements in innate NK cell response has also been shown with supplementation. ${ }^{36}$

\section{Zinc}

There is little zinc storage in the body, meaning that inadequate intakes can lead to deficiency, which is associated with compromised immune function. ${ }^{37}$ It is critical for the functioning of both innate and adaptive immunity, as well as cytokine production-which is altered during deficiency, contributing to oxidative stress and inflammation. ${ }^{38}{ }^{39}$ This role in mediating inflammatory response is particularly relevant in the systemic inflammatory response observed in sepsis, an over-reactive host response to infection. Low zinc status has been associated with increased susceptibility to sepsis and fatality to infection. ${ }^{40}$ This is complicated by the fact that pathogens require zinc to thrive, while the immune system also requires it to function, meaning status can appear to have a contradictory role in the infection process. ${ }^{41}$ Higher status ( $>70 \mathrm{mg} / \mathrm{dL}$ ) can be predictive of favourable pneumonia incidence and treatment course in the institutionalised elderly, ${ }^{42}$ which is an important consideration given that they are a high-risk group for deficiency.

Numerous RCTs have demonstrated that supplementation of moderate zinc doses in healthy elderly individuals improves several aspects of immune functioning and may reduce incidence of infections ${ }^{38}$ and even overall mortality. ${ }^{43}$ A recent Cochrane Review also found that supplementation reduced the risk of pneumonia by $13 \%$ in children under $5 .^{44}$ It is worth noting that high zinc intakes can increase copper losses and contribute to deficiency; therefore, supplementation should be combined with a copper component. ${ }^{45}$

\section{Selenium}

Selenium influences the immune response largely through its action in selenoproteins, which function as cellular antioxidants. ${ }^{46}$ Deficiency appears to enhance virulence or progression of some viral infections ${ }^{47}$ as evidenced by the relationship between Keshan disease, coxsackievirus B3 and influenza A, which are exacerbated by low Se status. Selenium also has an important role in the modulation of the inflammatory response and cytokine production. ${ }^{48}$

Supplementation of selenium improves the immune system response to viruses in deficient individuals. ${ }^{49}$ Although scarce evidence of this has been demonstrated in humans, limited studies have shown functional outcomes of selenium supplementation on the human immune system. In one trial of UK adults with poor selenium status, supplementation with selenium attenuated poliovirus more rapidly than those given a placebo. ${ }^{50}$ Caution is advised due to the adverse effects of selenium in high status and it is suggested those who are selenium sufficient should not supplement due to potential adverse effects. ${ }^{46} 48$

\section{HIGH-RISK GROUPS}

Certain individuals are at greater risk of micronutrient deficiency; this includes women of childbearing age (particularly pregnant and lactating women), younger children, adolescents (particularly females), older adults, ${ }^{51}$ obese individuals, the critically ill, individuals with inflammatory bowel disease ${ }^{52}$ and those with other chronic inflammatory and malabsorptive conditions. ${ }^{53}$ This risk, in the case of vitamin D especially, extends to those living at higher latitudes, as well as immigrant and black and minority ethnic (BAME) populations. ${ }^{54}$ Deficiencies are also observed in individuals due to the clinical management of disease itself, which can impact negatively on status. ${ }^{55}$ In many of these groups, a balanced diet alone may not be sufficient to meet micronutrient requirements and deficiencies can contribute to impaired immune function. This can be due to a variety of factors affecting intakes, absorption and also due to increased utilisation of micronutrients during times of infection. In such cases, the immune system can be supported by micronutrient supplementation, particularly to help correct deficiencies and attenuate the effects of concurrent treatments. The following section details the role of specific micronutrients in two primary groups affected during the COVID-19 pandemic, the elderly and the critically ill. It is important to make clear that this is not a complete list. Consideration should also be taken for other immunocompromised patients and the unknowns that exist within these groups related to interindividual differences in absorption, requirements and other mitigating factors.

There is a general deterioration of immune function associated with ageing, often termed immunosenescence, which affects both innate and adaptive immune systems. ${ }^{556}$ This results in diminished response to vaccination, ${ }^{57}$ impaired skin and mucous membrane function (due to dermal and subcutaneous atrophy, decreased production of IgA and reduced functional activity of immune cells) and longer inflammatory processes. ${ }^{58}$ For this reason, elderly individuals are more likely to contract infections, many of which last longer, putting them at increased risk of complications. ${ }^{51}$ Higher levels of micronutrient deficiencies exist in older adults in both community (vitamins $\mathrm{A}, \mathrm{B}_{12}, \mathrm{D}$ and zinc) and residential populations (vitamins $\mathrm{A}, \mathrm{D}$ and $\mathrm{E}$ ), ${ }^{51}{ }^{56}$ which has implications when admitted to the acute setting. This is due to a variety of factors influencing dietary intake and nutrient absorption, alongside increased requirements to compensate for deficits in cellular function and the 
stress response associated with ageing. ${ }^{41}$ This includes a reduced antioxidant production and vitamin $\mathrm{D}$ synthesis in skin. ${ }^{59}$ Overall, older people are 2-10 times more likely to die of infection than younger people. ${ }^{41}$

Elderly people are at higher risk of vitamin C deficiency, and once deficient are more likely to have a compromised immune system, infections and develop sepsis. ${ }^{17}$ Supplementation has reduced incidence and duration of RTI and severity of pneumonia in hospitalised older adults, while prophylactic supplementation has also been demonstrated to reduce the risk of acquiring pneumonia in patients with poor baseline status. ${ }^{22}$ Lower vitamin E status is commonly found in the elderly. ${ }^{41}$ Beneficial effects of supplementation have been observed in older institutionalised residents, with alpha-tocopherol shown to specifically enhance the dampened immune response associated with ageing. ${ }^{34}$ Zinc deficiency is more prevalent in the elderly and contributes to immunosenescense. Reduced immune function occurs even if deficiency is marginal, which is common in elderly populations due to plasma zinc concentration declining with age ${ }^{61}$ Zinc deficiency is common in the institutionalised elderly, and higher status $(>70 \mathrm{mg} / \mathrm{dL})$ appears to be predictive of lower pneumonia incidence and more favourable treatment outcomes. ${ }^{41}{ }^{56}$ RCTs have demonstrated that the supplementation of high doses $(45 \mathrm{mg})$ in healthy elderly individuals improves several aspects of immune functioning and reduces the incidence of infections. ${ }^{38}$

The role of micronutrients in mediating the inflammatory response is particularly relevant in the systemic inflammatory response observed in sepsis, an over-reactive host response to infection. ${ }^{41}$ Higher vitamin D status is associated with decreased levels of proinflammatory cytokines and conversely low status appears to be associated with the activation of inflammatory processes ${ }^{62}$ This could be particularly relevant when considering the relationship between vitamin $\mathrm{D}$ and the mediation of inflammation in critically ill patients. ${ }^{63}$ The activation of vitamin $\mathrm{D}$ in the lung has the potential to induce specific antimicrobials and attenuate inflammatory cytokines in response to viruses, which is particularly relevant in the case of sepsis derived from lung infection. ${ }^{28}$ Cytokine production is altered during zinc deficiency, contributing to oxidative stress and inflammation. ${ }^{38} 39$ Inadequate zinc status has been associated with increased susceptibility to sepsis and fatality to infection. ${ }^{41}$ This can have severe consequences in patients who require intensive care. ${ }^{64}$ Selenium has a role in the regulation of cytokines and deficiency is associated with clinical sepsis. In these patients, status can be predictive of outcomes ${ }^{48}$ and improved outcomes have been shown through supplementation in RCTs with systemic inflammatory response syndrome. ${ }^{65}$

\section{PREVENTATIVE HEALTHCARE: IMPLICATIONS FOR POLICY, PRACTICE AND FUTURE RESEARCH}

It is clear that specific micronutrients have an important role to play in the functioning of the immune system.
Deficiencies in these micronutrients are widespread, particularly among vulnerable population groups, comprising many of those at the highest risk of morbidity and mortality during the COVID-19 pandemic. ${ }^{11} 606266$ As practitioners and policy-makers, we have a duty to pay attention to these facts and consider measures to mitigate some of these modifiable risk factors. It is important to be aware that malnutrition is a very real problem in the developed nations. We have seen data from the UK National Diet and Nutrition Survey ${ }^{67}$ and wider world ${ }^{3}$ that suggests that malnutrition and micronutrient deficiencies are prevalent in a significant proportion of our most vulnerable groups. ${ }^{754566668}$ While these deficiencies may not be clear on the surface, the effects of poor micronutrient status are observed in infectious disease prevalence and influence disease severity. Tackling these issues prior to their occurrence will contribute to reducing susceptibility, while correcting insufficiencies and deficiencies during disease may also contribute to favourable disease course and outcomes. ${ }^{69}$

\section{Policy}

The role of nutritional status cannot be overlooked. The first port of call should be, and largely has been, a focus on consuming a well-balanced diet. Eating foods from a variety of food groups will often be sufficient to meet energy, protein and micronutrient requirements in the general population. Hence, a primary recommendation for public health risk communication and recommendations for nutrition and dietary intake is to encourage compliance with national dietary guidance, such as the Eat Well Guide for the UK, ${ }^{70}$ which endeavours to supply sufficient macronutrient and micronutrient intake for the general population. With this in mind, aiming to improve overall dietary diversity in the general population will be extremely important, especially under the current constraints. For many, however, this may not be enough. It is important to remember that supplementation should not be considered as a replacement, but instead as an addition to good dietary practices if and when it is necessary. This can be achieved through a number of means. A good example is vitamin $\mathrm{D}$, which is widely recommended to the general population to be supplemented in order to reduce the risk of deficiency and associated disease. ${ }^{66} 7172$ This is warranted during periods of the year when insufficient sunlight is available to meet requirements ${ }^{66}$ and also in population groups who are considered at high risk..$^{5567}$ Notably older, housebound individuals, those living at higher latitudes and BAME populations fall into this category meaning that vitamin $\mathrm{D}$ supplementation will likely be required to achieve adequacy in these groups. ${ }^{5466} 68$ This is particularly important given the current need for self-quarantine and cocooning through the COVID-19 pandemic, meaning access to sufficient sunlight may be an issue. ${ }^{54668}$ In fact, there have been calls for supplementation at higher levels to achieve adequacy in the elderly population during such a vulnerable period. ${ }^{11} 73$ Seasonal fluctuations in vitamin D status could also be 
avoided through wider policy and have the potential to support good health, in general as well as during the significant challenges posed by COVID-19. ${ }^{54}$ Based on this evidence, it appears sensible to consider mass communication of the prevalence and implications of vitamin D deficiency, and safe to recommend wide supplementation which is currently set at $400 \mathrm{IU} /$ day $(10 \mu \mathrm{g} /$ day $)$ for the UK; $600 \mathrm{IU} /$ day $(15 \mu \mathrm{g} /$ day $)$ for the USA (800 IU/ day $(20 \mu \mathrm{g} /$ day $)$ for $>70$ years $)$ and Europe ${ }^{66}$ to avoid suboptimal status and the potential risk of compromised immune function. This is especially important in those at the highest risk of deficiencies. ${ }^{546} 73$ Other potential policy methods include mandatory fortification, which in Finland has been effective in reducing levels of deficiency to less than $1 \%$ of the population, ${ }^{74}$ and may warrant further consideration. It would also be useful to better define the level of deficiency in other key micronutrients (vitamin C, zinc), and consider measures to ensure adequacy in these in high-risk groups. ${ }^{56}$

\section{Practice}

For practitioners, it is important to be aware that micronutrient deficiencies are rarely recognised in daily practice, but are highly prevalent in the UK, particularly in these groups at high risk of contracting COVID-19. ${ }^{54} 6673$ Practitioners should be aware of this fact and consider it during both the screening and treatment process in COVID-19. In some individuals, diet alone may not be sufficient to achieve the intakes of these nutrients required to prevent deficiency. This can be related to the increased demands of age, disease and numerous other factors mentioned above. In these groups, the evidence presented in this piece suggests that supplementation for the correction of status may be a serious and clinically relevant consideration. Of particular interest appear to be of vitamins $\mathrm{C}$ and $\mathrm{D}$, given their role in the prevention and treatment of RTIs. ${ }^{21} 22{ }^{24}{ }^{25}$ With recent evidence suggesting a limited benefit of vitamin $\mathrm{C}$ therapy in the treatment of sepsis and ARDS, ${ }^{23}$ this may have a more important role in prevention rather than treatment, or may have beneficial effects when treating patients with COVID-19 who also have a superimposed pneumonia. ${ }^{22}$ The high rate of temporary renal replacement therapy required in patients with COVID $^{75}$ should also be considered, as this too can have an impact on micronutrient status and therefore increase requirements. ${ }^{76}$ Beyond this, there is evidence to suggest that the correction of micronutrient deficiencies in established disease can contribute to supporting the immune response to infection in those at highest risk. Zinc and selenium play a vital role in immune functioning, through exerting influence on the inflammatory process ${ }^{38} 48$ as does vitamin D. ${ }^{63}$ All three have been suggested to be effective in mediating the inflammatory response observed in sepsis, ${ }^{28} 4063-65$ which is of particular relevance when considering severe complications COVID-19. This is observed in the systemic immune-mediated inflammatory response and associated 'cytokine storm', which has the potential to signal the onset of ARDS and ultimately, increase the risk of death. ${ }^{77}$ Therefore, the role of these key micronutrients, or perhaps more importantly the consequences of inadequate status, could be a worthwhile consideration for clinical practice..$^{55-5760}$

\section{Research}

With the recent identification of specific immune responses to COVID- $19,{ }^{78}$ now is the time to consider additional measures that can support optimal functioning of the immune system. Granted, in the case of nutritional immunology, the discrepancy in results from many studies adds the challenge of interpreting this into clinical practice. ${ }^{41}$ While there is no clear consensus at this time regarding the clinical relevance of these micronutrients, results from trial data are encouraging and suggestive of significant effects. In some cases, however, results in human studies are not always consistent with preclinical animal models, or the immunomodulatory effects have not yet been examined in humans. ${ }^{41}$ As this research develops further, there is a need for more standardised clinical trials, the assurance of quality in analytical measurements ${ }^{79}$ and better characterised populations to establish optimal doses for maximum clinical benefits, which will vary depending on a variety of group and interindividual differences, a number of which have been discussed above.

\section{CONCLUSION}

There are as of yet few, if any published studies on the precise role of nutrition in the prevention or treatment of COVID-19. Defining this to provide evidence-informed guidelines will require more carefully designed studies, that first use available data from population and patient sources. This should be followed by ethically approved and applicable intervention studies, where the data suggest that these are appropriate. Unfortunately, given the speed at which the situation is developing, this has been challenging. In the absence of such evidence, the best option has been to synthesise published evidence and make reasonable assumptions and extrapolations based on previous knowledge of the relationship between nutrition, immunity and infections. What is clear is that conditions of nutrient deficiency impair the functioning of the immune system and increase susceptibility to infection. Importantly, both of these consequences can be reversed by correcting the deficiency. For now, there is a strong case to be made for a focus on achieving micronutrient adequacy alongside attention to overall nutritional status, which has proven to play an important part in infection prevention and treatment, particularly in those at highest risk.

\section{Author affiliations}

${ }^{1}$ NNEdPro Global Centre for Nutrition and Health, St John's Innovation Centre, Cambridge, UK

${ }^{2}$ School of Biomedical Sciences, Ulster University at Coleraine, Coleraine, Northern Ireland 
${ }^{3}$ School of Humanities and Social Sciences, University of Cambridge, Cambridge, UK ${ }^{4}$ Maldon District Council, Council Offices, Maldon, UK ${ }^{5}$ Imperial College London NHS Foundation Trust, London, UK

${ }^{6}$ UNC Nutrition Research Institute, University of North Carolina at Chapel Hill, Kannapolis, North Carolina, USA

Twitter Shane McAuliffe @ShaneMacZ, Sumantra Ray @ProfSumantraRay, Emily Fallon@EmilyFallon_, James Bradfield @braddybradfield and Timothy Eden @ TimothyEdenRD

Acknowledgements The NNEdPro COVID-19 Taskforce-Dominic Crocombe \& Sucheta Mitra https://www.nnedpro.org.uk/coronavirus.

Contributors SM: conceptualisation of review and writing content. SR: conceptualisation, overall responsibility for supervision of content, iterative review and input. EF and MK: conceptualisation, iterative review and input. JB and TE: reviewed and commented substantively.

Funding The authors have not declared a specific grant for this research from any funding agency in the public, commercial or not-for-profit sectors.

Competing interests None declared.

Patient consent for publication Not required.

Provenance and peer review Not commissioned; externally peer reviewed.

Data availability statement Data sharing not applicable as no datasets generated and/or analysed for this study.

Author note Twitter handle for NNEdPro: https://twitter.com/NNEdPro.

Open access This is an open access article distributed in accordance with the Creative Commons Attribution Non Commercial (CC BY-NC 4.0) license, which permits others to distribute, remix, adapt, build upon this work non-commercially, and license their derivative works on different terms, provided the original work is properly cited, appropriate credit is given, any changes made indicated, and the use is non-commercial. See: http://creativecommons.org/licenses/by-nc/4.0/.

\section{ORCID iDs}

Shane McAuliffe http://orcid.org/0000-0002-7166-4299

James Bradfield http://orcid.org/0000-0002-1010-2372

Martin Kohlmeier http://orcid.org/0000-0003-1478-1744

\section{REFERENCES}

1 Bourke CD, Berkley JA, Prendergast AJ. Immune dysfunction as a cause and consequence of malnutrition. Trends Immuno 2016;37:386-98

2 Nájera O, González C, Toledo G, et al. Flow cytometry study of lymphocyte subsets in malnourished and well-nourished children with bacterial infections. Clin Diagn Lab Immunol 2004;11:577-80.

3 Leij-Halfwerk S, Verwijs MH, van Houdt S, et al. Prevalence of protein-energy malnutrition risk in European older adults in community, residential and hospital settings, according to 22 malnutrition screening tools validated for use in adults $\geq 65$ years: a systematic review and meta-analysis. Maturitas 2019;126:80-9.

4 Finucane F, Davenport C. Could insulin resistance mediate the severity of Covid-19 infection? Front Public Health 2020.

5 EvansP, Halliwell B. Micronutrients: oxidant/antioxidant status. $\mathrm{Br} \mathrm{J}$ Nutr 2001;85 Suppl 2:S67.

6 Maggini S, Wintergerst ES, Beveridge S, et al. Selected vitamins and trace elements support immune function by strengthening epithelial barriers and cellular and humoral immune responses. Br J Nutr 2007;98 Suppl 1:S29-35.

7 Calder PC. Nutrition, immunity and COVID-19. BMJNPH 2020;30:e000085:bmjnph-2020-000085.

8 World Health organization influenza (seasonal). Available: https:// www.who.int/news-room/fact-sheets/detail/influenza-(seasonal) [Accessed 30 Mar 2020].

9 Global, regional, and national age-sex specific all-cause and causespecific mortality for 240 causes of death, 1990-2013: a systematic analysis for the global burden of disease study 2013. The Lancet 2015;385:117-71.

10 Rudd KE, Johnson SC, Agesa KM, et al. Global, regional, and national sepsis incidence and mortality, 1990-2017: analysis for the global burden of disease study. The Lancet 2020;395:200-11.

11 Calder PC, Carr AC, Gombart AF, et al. Optimal nutritional status for a Well-Functioning immune system is an important factor to protect against viral infections. Nutrients 2020;12:2020030199.
12 Alpert PT. The role of vitamins and minerals on the immune system. Home Health Care Manag Pract 2017;29:199-202.

13 Semba RD. The role of vitamin A and related retinoids in immune function. Nutr Rev 2009;56:S38-48.

14 Imdad A, Yakoob MY, Sudfeld C, et al. Impact of vitamin A supplementation on infant and childhood mortality. BMC Public Health 2011;11 Suppl 3:S20.

15 Padayatty SJ, Katz A, Wang Y, et al. Vitamin C as an antioxidant: evaluation of its role in disease prevention. J Am Coll Nutr 2003;22:18-35.

16 Carr AC, Maggini S. Vitamin C and immune function. Nutrients 2017;9:1211.

17 Bakaev VV, Duntau AP. Ascorbic acid in blood serum of patients with pulmonary tuberculosis and pneumonia. Int $J$ Tuberc Lung Dis 2004;8:263-6.

18 Hemilä H. Vitamin C and infections. Nutrients 2017;9:339.

19 Fisher BJ, Kraskauskas D, Martin EJ, et al. Mechanisms of attenuation of abdominal sepsis induced acute lung injury by ascorbic acid. Am J Physiol Lung Cell Mol Physiol 2012;303:L20-32.

20 Hunt C, Chakravorty NK, Annan G. The clinical and biochemical effects of vitamin $\mathrm{C}$ supplementation in short-stay hospitalized geriatric patients. Int J Vitam Nutr Res 1984;54:65-74.

21 Hemilä H, Chalker E. Vitamin C for preventing and treating the common cold. Cochrane Database Syst Rev 2013:CD000980.

22 Hemilä H, Louhiala P. Vitamin C for preventing and treating pneumonia. Cochrane Database Syst Rev 2013:CD005532.

23 Fowler AA, Truwit JD, Hite RD, et al. Effect of vitamin C infusion on organ failure and biomarkers of inflammation and vascular injury in patients with sepsis and severe acute respiratory failure: the CITRISALI randomized clinical trial. JAMA 2019;322:1261.

24 Holick MF. High prevalence of vitamin D inadequacy and implications for health. Mayo Clin Proc 2006;81:353-73.

25 Kroner JdeC, Sommer A, Fabri M. Vitamin D every day to keep the infection away? Nutrients 2015;7:4170-88.

26 Hewison M. Antibacterial effects of vitamin D. Nat Rev Endocrinol 2011;7:337-45.

27 Chen H, Lu R, Zhang Y-G, et al. Vitamin D receptor deletion leads to the destruction of tight and adherens junctions in lungs. Tissue Barriers 2018;6:1-13.

28 Hansdottir S, Monick MM, Hinde SL, et al. Respiratory epithelial cells convert inactive vitamin $\mathrm{D}$ to its active form: potential effects on host defense. J Immunol 2008;181:7090-9.

29 Martineau AR, Jolliffe DA, Hooper RL, et al. Vitamin D supplementation to prevent acute respiratory tract infections: systematic review and meta-analysis of individual participant data. BMJ 2017;356:i6583.

30 Martineau AR, James WY, Hooper RL, et al. Vitamin D3 supplementation in patients with chronic obstructive pulmonary disease (ViDiCO): a multicentre, double-blind, randomised controlled trial. Lancet Respir Med 2015;3:120-30.

31 Jolliffe DA, Greenberg L, Hooper RL, et al. Vitamin D supplementation to prevent asthma exacerbations: a systematic review and meta-analysis of individual participant data. Lancet Respir Med 2017;5:881-90.

32 Traber MG, Atkinson J. Vitamin E, antioxidant and nothing more. Free Radic Biol Med 2007:43:4-15.

33 Moriguchi S, Muraga M. Vitamin E and immunity. Vitam Horm 2000;59:305-36.

34 Wu D, Meydani SN. Age-Associated changes in immune function: impact of vitamin $E$ intervention and the underlying mechanisms. Endocr Metab Immune Disord Drug Targets 2014;14:283-9.

35 Alpha-Tocopherol, Beta Carotene Cancer Prevention Study Group. The effect of vitamin $\mathrm{E}$ and beta carotene on the incidence of lung cancer and other cancers in male smokers. $N$ Engl J Med 1994;330:1029-35.

36 De la Fuente M, Hernanz A, Guayerbas N, et al. Vitamin E ingestion improves several immune functions in elderly men and women. Free Radic Res 2008;42:272-80.

37 Ibs K-H, Rink L. Zinc-altered immune function. J Nutr 2003;133:1452S-6.

38 Prasad AS, Beck FWJ, Bao B, et al. Zinc supplementation decreases incidence of infections in the elderly: effect of zinc on generation of cytokines and oxidative stress. Am J Clin Nutr 2007;85:837-44.

39 Foster M, Samman S. Zinc and regulation of inflammatory cytokines: implications for cardiometabolic disease. Nutrients 2012;4:676-94.

40 Souffriau J, Libert C. Mechanistic insights into the protective impact of zinc on sepsis. Cytokine Growth Factor Rev 2018;39:92-101.

41 Wu D, Lewis ED, Pae M, et al. Nutritional modulation of immune function: analysis of evidence, mechanisms, and clinical relevance. Front Immunol 2018;9:3160. 
42 Meydani SN, Barnett JB, Dallal GE, et al. Serum zinc and pneumonia in nursing home elderly. Am J Clin Nutr 2007;86:1167-73.

43 Chew EY, Clemons TE, Agrón E, et al. Long-Term effects of vitamins $\mathrm{C}$ and $\mathrm{E}, \beta$-carotene, and zinc on age-related macular degeneration: AREDS report No. 35. Ophthalmology 2013;120:1604-11.

44 Lassi ZS, Moin A, Das JK, et al. Systematic review on evidencebased adolescent nutrition interventions. Ann N Y Acad Sci 2017; 1393:34-50.

45 Duncan A, Yacoubian C, Watson N, et al. The risk of copper deficiency in patients prescribed zinc supplements. J Clin Pathol 2015;68:723-5.

46 Rayman MP. Selenium and human health. The Lancet 2012;379:1256-68.

47 Kiremidjian-Schumacher L, Roy M, Glickman R, et al. Selenium and immunocompetence in patients with head and neck cancer. Biol Trace Elem Res 2000;73:97-112.

48 Huang Z, Rose AH, Hoffmann PR. The role of selenium in inflammation and immunity: from molecular mechanisms to therapeutic opportunities. Antioxid Redox Signal 2012;16:705-43.

49 Hoffmann PR, Berry MJ. The influence of selenium on immune responses. Mol Nutr Food Res 2008;52:1273-80.

50 Broome CS, McArdle F, Kyle JAM, et al. An increase in selenium intake improves immune function and poliovirus handling in adults with marginal selenium status. Am J Clin Nutr 2004;80:154-62.

51 Maggini S, Pierre A, Calder PC. Immune function and micronutrient requirements change over the life course. Nutrients 2018;10:1531.

52 Kilby K, Mathias H, Boisvenue L, et al. Micronutrient absorption and related outcomes in people with inflammatory bowel disease: a review. Nutrients 2019;11:1388

53 Keller J, Layer P. The Pathopysiology of malabsorption. Viszeralmedizin 2014;30:7

54 Kohlmeier M. Avoidance of vitamin D deficiency to slow the COVID-19 pandemic. BMJNPH 2020;3:e000096.

55 Fulop T, Witkowski JM, Pawelec G, et al. On the immunological theory of aging. Interdiscip Top Gerontol 2014;39:163-76.

56 Derbyshire E, Delange J. COVID-19: is there a role for immunonutrition, particularly in the over $65 \mathrm{~s}$ ? BMJNPH 2020;3:e000071.

57 Calder PC. Feeding the immune system. Proc Nutr Soc 2013;72:299-309.

58 Castelo-Branco C, Soveral I. The immune system and aging: a review. Gynecol Endocrinol 2014;30:16-22.

59 Liguori I, Russo G, Curcio F, et al. Oxidative stress, aging, and diseases. Clin Interv Aging 2018;13:757-72.

60 Gallagher JC. Vitamin D and aging. Endocrinol Metab Clin North Am 2013;42:319-32.

61 Wong $\mathrm{CP}$, Ho E. Zinc and its role in age-related inflammation and immune dysfunction. Mol Nutr Food Res 2012;56:77-87.

62 Zittermann A, Pilz S, Hoffmann H, et al. Vitamin D and airway infections: a European perspective. Eur J Med Res 2016;21:14.
63 Amrein K, Papinutti A, Mathew E, et al. Vitamin D and critical illness: what endocrinology can learn from intensive care and vice versa. Endocr Connect 2018;7:R304-15

64 Besecker BY, Exline MC, Hollyfield J, et al. A comparison of zinc metabolism, inflammation, and disease severity in critically ill infected and noninfected adults early after intensive care unit admission. Am $J$ Clin Nutr 2011;93:1356-64.

65 Forceville X. Effects of high doses of selenium, as sodium selenite, in septic shock patients a placebo-controlled, randomized, doubleblind, multi-center phase II study--selenium and sepsis. J Trace Elem Med Biol 2007;21 Suppl 1:62-5.

66 Lanham-New SA, Webb AR, Cashman KD, et al. Vitamin D and SARS-CoV-2 virus/COVID-19 disease. BMJNPH 2020;3:e000089.

67 National diet and nutrition survey, 2019. Available: https://www.gov. uk/government/collections/national-diet-and-nutrition-survey

68 Griffin TP, Wall D, Blake L, et al. Vitamin D status of adults in the community, in outpatient clinics, in hospital and in nursing homes in the West of Ireland. J Gerontol A Biol Sci Med Sci 2020. doi:10.1093/ gerona/glaa010. [Epub ahead of print: 14 Jan 2020].

69 Eden T, Rajput-Ray M, Ray S. Micronutrient and vitamin physiology and requirements in critically ill patients. Nutrition in Critical Care:3342.

70 England PH. The Eatwell guide. helping you eat a healthy, balanced diet. London: Public Health England, 2016.

71 Scientific Advisory Committee on Nutrition (SACN). Vitamin D, 2016.

72 Institute of Medicine. Dietary reference intakes for calcium and vitamin D. Washington, DC, USA.2011

73 Vitamin D deficiency in Ireland - implications for COVID-19. Results from the Irish longitudinal study on ageing (TILDA), 2019.

74 Jääskeläinen $\mathrm{T}$, Itkonen ST, Lundqvist $\mathrm{A}$, et al. The positive impact of general vitamin $\mathrm{D}$ food fortification policy on vitamin $\mathrm{D}$ status in a representative adult Finnish population: evidence from an 11-y follow-up based on standardized 25-hydroxyvitamin D data. Am J Clin Nutr 2017:105:1512-20.

75 BDA Clinical Care Specialist Group (CCSG). Guidance on management of nutrition and dietetic services during the COVID-19 pandemic, 2020. Available: https://www.bda.uk.com/resource/ critical-care-dietetics-guidance-covid-19.html

76 Brochard L, Abroug F, Brenner M, et al. An official ATS/ERS/ ESICM/SCCM/SRLF statement: prevention and management of acute renal failure in the ICU patient. Am J Respir Crit Care Med 2010;181:1128-55.

77 Pedersen SF, Ho Y-C. SARS-CoV-2: a storm is raging. J Clin Invest 2020;130:2202-5.

78 Thevarajan I, Nguyen THO, Koutsakos M, et al. Breadth of concomitant immune responses prior to patient recovery: a case report of non-severe COVID-19. Nat Med 2020;26:453-5.

79 Höller U, Bakker SJL, Düsterloh A, et al. Micronutrient status assessment in humans: current methods of analysis and future trends. TrAC Trends in Analytical Chemistry 2018;102:110-22. 